Revista Verde de Agroecologia e Desenvolvimento Sustentável

http://www.gvaa.com.br/revista/index.php/RVADS

ARTIGO CIENTÍFICO

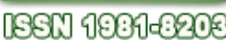

DOI: http://dx.doi.org/10.18378/rvads.v10i4.3415

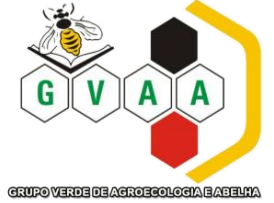

\title{
Parâmetros físico-químicos de polpas de fruta produzidas na cidade de Petrolina - PE
}

\section{Physicochemical parameters of fruit pulps produced in Petrolina - PE}

\author{
Alan Cunha Honorato ${ }^{l}$, Conrado Bastnen Ribeiro Dias ${ }^{l}$, Elder Barboza de Souza ${ }^{l}$, Itamara Rayanny Bessa de Carvalho ${ }^{l}$, \\ Karla dos Santos Melo de Sousa ${ }^{2}$
}

Resumo: Este trabalho teve como objetivo avaliar os parâmetros físico-químicos de polpas de fruta produzidas e comercializadas na cidade de Petrolina-PE, tendo como referência a Instrução Normativa nº 1 , de 7 jan. 2000, do Ministério da Agricultura que define as características físicas e químicas estabelecendo limites mínimos e máximos específicos para cada polpa de fruta. Foram avaliadas duas marcas (1 e 2) de polpas de abacaxi, cacau, caju, graviola, maracujá e umbu, analisadas quanto aos parâmetros de $\mathrm{pH}$, sólidos solúveis totais (SST), acidez total titulável (ATT), ácido ascórbico, relação SST/ATT e sólidos totais. Os resultados permitem inferir que a marca 2 apresentou qualidade superior na maioria dos parâmetros avaliados quando comparado com a marca 1. Entretanto para alguns sabores de polpa as duas marcas não atenderam os valores padrões. Entre as polpas o único sabor que apresentou os padrões exigidos foi a polpa de caju em ambas as marcas, e a que apresentou resultado de pior qualidade diante dos padrões foi a polpa de maracujá principalmente da marca 1 . Dessa forma constata-se que há grandes variações entre as marcas, e entre alguns parâmetros, o que compromete a qualidade das polpas, prejudicando assim o consumidor.

Palavras-chaves: Padrão de Identidade e Qualidade, controle de qualidade, legislação.

Abstract: This study aimed to evaluate the physicochemical parameters of fruit pulps produced and marketed in the city of Petrolina-PE, with reference to the Instruction $N^{\circ} 1$ of 7 January 2000 of the Ministry of Agriculture, which defines the physical and chemical characteristics setting minimum and maximum limits specific to each fruit pulp. We evaluated two brands ( 1 and 2) of pineapple, cocoa, cashew, soursop, passion and umbu fruit pulp, analyzed for $\mathrm{pH}$, total soluble solids (TSS), total titratable acidity (TTA), ascorbic acid, TSS / TTA and total solids parameters. Results show that the brand 2 showed superior in most evaluated parameters when compared to the brand 1. However, for some pulp flavors of both brands did not reached the standards values. Among the pulps, the only flavor that presented the required standards was the cashew pulp in both brands, and presented the results of lower quality on the standards was the passion fruit pulp mainly brand 1. Thus, it appears that there are great variations between brands and between some parameters, which compromises the quality of the pulp, thus impairing the consumer.

Key words: Quality and Identity Standard, quality control, legislation.

\footnotetext{
*Autor para correspondência

Recebido para publicação em 25/05/2015; aprovado em 20/09/2015
}

\footnotetext{
${ }^{1}$ Graduandos de Engenharia Agronômica, Colegiado de Engenharia Agronômica - UNIVASF - Universidade Federal do Vale do São Francisco Petrolina PE. E-mail: alan_honorato18@hotmail.com, conradobastenen@hotmail.com, elder.barboza@hotmail.com, itamara.rayanny@hotmail.com.

${ }^{2}$ Eng. Agrícola, D. Sc., Professora Adjunto II do Colegiado de Engenharia Agronômica - UNIVASF - Universidade Federal do Vale do São Francisco, Rodovia BR 407 - KM 119 - Lote 543 PSNC, s/nº - C1, CEP: 56300-990, Petrolina - PE. E-mail: karla.smsousa@ univasf.edu.br.
} 


\section{INTRODUÇÃO}

O Brasil é o maior produtor mundial de frutas in natura, porém, por serem perecíveis, grande parte dessas frutas sofre deterioração em poucos dias, tendo sua comercialização dificultada, especialmente a longas distâncias (MORAIS, 2010).

O consumo de sucos processados vem aumentando a cada dia, motivado pela falta de tempo da população em preparar suco das frutas in natura, pela praticidade que tais produtos oferecem e pela substituição ao consumo de bebidas carbonatadas devido ao seu valor nutritivo e preocupação com o consumo de alimentos mais saudáveis (MATSUURA, 2002).

$\mathrm{O}$ mercado de polpas congeladas de frutas tem apresentado expressivo crescimento nos últimos anos, notadamente no Nordeste brasileiro, com grande potencial mercadológico, especialmente pela variedade de frutas e sabores agradáveis. Porém, a grande variedade de sabores não contemplados na legislação, aliado ao crescimento do mercado informal, podem levar à comercialização de produtos sem uniformidade e sem controle sanitário adequado, pois as unidades fabris se compõem, em sua maioria, de pequenos produtores, onde grande parte deles utilizam processos artesanais, sem a devida observância das técnicas adequadas de processamento (MACHADO, 2009).

No Brasil a qualidade de polpas de fruta comercializadas é regulamentada pela Instrução Normativa de $\mathrm{N}^{\circ} 1$ de 07 de janeiro de 2000 que determina os Padrões de Identidade e Qualidade (PQI's). Esta legislação define polpa de fruta como sendo o produto não fermentado, não concentrado, não diluído, obtida de frutos polposos, através de processo tecnológico adequado, com um teor mínimo de sólidos totais, proveniente da parte comestível do fruto (BRASIL, 2000).

A importância nutricional das frutas para a humanidade é inquestionável, graças a seus conteúdos de vitaminas e sais minerais, no entanto, estas apresentam alta perecibilidade o que leva ainda hoje a grandes perdas. Deste modo, o processamento de frutas para obtenção de polpas é uma atividade agroindustrial importante por principalmente garantir o aproveitamento do excedente no período de safra (ARRUDA et al., 2006).

As características físicas, químicas e organolépticas das polpas devem ser as provenientes do fruto de origem e não podem ser alteradas pelos equipamentos, utensílios, recipientes e embalagens utilizadas durante $o$ seu processamento e comercialização. Os parâmetros físicoquímicos que indicam a qualidade das polpas são: $\mathrm{pH}$, sólidos solúveis totais, açúcares totais, acidez total titulável e ácido ascórbico (BRASIL, 2000).

Em análise de alimentos, é de suma importância à determinação dos seus componentes como é o caso da determinação da composição centesimal, estes procedimentos são realizados com a finalidade de fornecer informações sobre a composição química, físico-química e, ou, física do alimento (GADELHA et al., 2009).

Desta forma o presente trabalho tem como objetivo a caracterização físico-química de polpas de frutas congeladas, produzidas e comercializadas em Petrolina/PE nos sabores (abacaxi, cacau, caju, graviola, maracujá e umbu).

\section{MATERIAL E MÉTODOS}

As polpas de frutas congeladas, produzidas e comercializadas em Petrolina-PE, foram escolhidas de forma aleatória. Foram utilizadas duas marcas de polpa de frutas, designadas marca 1 e marca 2, nos sabores de maracujá, caju, umbu, abacaxi, cacau e graviola adquiridas no mercado local.

As amostras foram transportadas em caixa térmica com gelo até o laboratório de Química Analítica da Universidade Federal do Vale do São Francisco - UNIVASF, Campus Ciências Agrárias, Petrolina - PE, para posterior realização das análises, onde foram mantidas congeladas em freezer com temperatura de $-18^{\circ} \mathrm{C}$

Para a caracterização físico-química das amostras foram analisados os parâmetros: $\mathrm{pH}$, determinado por medida direta, com potenciômetro de bancada; sólidos solúveis totais $\left({ }^{\circ} \mathrm{Brix}\right)$ através de leitura direta em refratômetro tipo Abbe com resultados corrigidos para a temperatura de $20^{\circ} \mathrm{C}$; acidez total titulável (ATT), relação SST/ATT (ratio); e sólidos totais (ST) de acordo com a metodologia proposta pelo Instituto Adolfo Lutz (BRASIL, 2008); e o ácido ascórbico utilizandose as metodologias descritas pela AOAC (1997), modificado por Benassi \& Antunes (1988). Os resultados encontrados foram comparados com os estabelecidos pelo Ministério da Agricultura Pecuária e Abastecimento na Instrução Normativa $\mathrm{n}^{\circ}$ 01, de 07 de janeiro de 2000 (quando na existência de parâmetros de referência) que regulamenta os limites permitidos dos parâmetros físico-químicos. Para as amostras de polpa de abacaxi e umbu os resultados foram comparados com valores encontrados na literatura.

Os dados experimentais encontrados foram submetidos a analises estatísticas utilizando-se o programa computacional ASSISTAT versão 6.0 Beta (SILVA \& AZEVEDO, 2002), tendo sido empregado o delineamento inteiramente casualizado com a comparação entre médias pelo teste de Tukey em nível de 5\% de significância, para a comparação de médias entre os tratamentos (marca 1 e marca 2).

\section{RESULTADOS E DISCUSSÃO}

Os valores de $\mathrm{pH}$ encontrados nas analises das polpas de todos os sabores e marcas estão dentro do estabelecido pelo Padrão de Identidade e Qualidade (PIQ), exceto as amostras de abacaxi e umbu que não tem referência neste documento (BARSIL, 2000). É possível observar também que estatisticamente a marca 1 foi a que apresentou os maiores valores de $\mathrm{pH}$ entre todas os sabores. Sendo que entre as marcas a polpa de caju foi a que apresentou maior variação com 4,50 e 3,77, marca 1 e 2 respectivamente (Tabela 1).

Como não existem padrões para as polpas de umbu e abacaxi foram feitas comparações dos resultados com dados encontrados na literatura. Sendo assim, é possível observar que os valores de $\mathrm{pH}$ da polpa de umbu foram 2,64 e 2,58 para as marcas 1 e 2 , respectivamente (Tabela 1), e estes valores são um pouco superiores aos resultados obtidos por Lima et al. (2003) e Silva et al. (2011), que encontraram valores médios de 2,16, e 2,47 respectivamente. Já os valores de $\mathrm{pH}$ encontrados nas polpas de abacaxi foram 3,84 para a marca 1 e 4,00 para a marca 2, também superiores aos resultados de Pinheiro et al. (2006) ao encontrarem valor médio de 3,52. Esta variação dos resultados pode estar associada a forma de manejo e local de coleta dos frutos, o 
que torna evidente a necessidade de se estabelecer PQI's normatizados para uma melhor avaliação destas polpas de frutas comercializadas.

Os valores de ${ }^{\circ}$ Brix da polpa de abacaxi encontrados foram 13,66 e $11,74^{\circ}$ Brix (Tabela 1 ), para marca 1 e marca 2, respectivamente, Caldas, (2010), Pinheiro, (2006) e Dantas, (2010) encontraram médias de 13,78, 12,18 e 13,13, respectivamente, para o mesmo fruto. Nota-se que a marca 2 apresentou os menores valores de sólidos solúveis totais. Para a polpa de umbu, o resultado foi oposto, a marca 2 $\left(11,07^{\circ}\right.$ Brix $)$ apresentou maiores valores quando comparada a marca $1\left(7,74^{\circ}\right.$ Brix). Esta variação entre marcas também foi observada por Machado et al. (2007) ao trabalharem com quatro diferentes marcas de polpa de umbu. É importante ressaltar que os valores de sólidos solúveis podem variar com a intensidade de chuva durante a safra, fatores climáticos, variedade, solos, além da adição eventual de água durante o processamento por alguns produtores, causando diminuição dos teores de sólidos solúveis no produto final (SANTOS et al., 2004).

Ainda em relação aos sólidos solúveis totais ( $\left.{ }^{\circ} \mathrm{Brix}\right)$ é possível observar que a marca 2 foi superior estatisticamente na maioria das polpas, tendo como exceção apenas a polpa de abacaxi. Os resultados permitem inferir ainda que as amostras de caju e graviola estão dentro dos valores estabelecidos pelo PIQ e que as amostras de maracujá e cacau não apresentam os valores mínimos estabelecidos pelos padrões (BRASIL, 2000) para as duas marcas, mostrando assim certa negligencia dos fabricantes quanto a estes produtos. Sólidos solúveis são usados como índice de maturidade para alguns frutos, e indicam a quantidade de substâncias que se encontram dissolvidos no suco ou polpa, sendo constituído em sua maioria por açúcares (BATISTA, 2013), isto indica que as polpas de maracujá e cacau podem estar sendo diluídas no momento de fabricação ou as frutas para quais foram feitas as polpas estavam com grau de maturação inadequado.

Tabela 1 - Características físico-químicas e de polpas de frutas congeladas comercializadas em Petrolina - PE

\begin{tabular}{|c|c|c|c|c|c|c|}
\hline \multirow[b]{3}{*}{ Amostras } & \multicolumn{6}{|c|}{ Características Físico-químicas } \\
\hline & \multirow[b]{2}{*}{$\mathrm{pH}$} & \multirow{2}{*}{$\begin{array}{l}\text { SST } \\
\left({ }^{\circ} \text { Brix }\right)\end{array}$} & \multirow{2}{*}{$\begin{array}{l}\text { ATT (g de ácido } \\
\text { cítrico/100 g) }\end{array}$} & \multicolumn{3}{|c|}{ Ácido Ascórbico (mg/100 } \\
\hline & & & & Ratio & g) & $\mathrm{ST}(\mathrm{g} / 100 \mathrm{~g})$ \\
\hline \multicolumn{7}{|l|}{ Maracujá } \\
\hline Marca 1 & $3,30 \mathrm{a}$ & $7,99 \mathrm{~b}$ & $1,93 \mathrm{~b}$ & $4,15 \mathrm{a}$ & $9,47 \mathrm{a}$ & $7,63 \mathrm{~b}$ \\
\hline Marca 2 & $3,16 \mathrm{~b}$ & $10,66 \mathrm{a}$ & $3,09 \mathrm{a}$ & $3,45 \mathrm{~b}$ & $9,11 \mathrm{a}$ & $9,99 \mathrm{a}$ \\
\hline \multicolumn{7}{|l|}{ Abacaxi } \\
\hline Marca 1 & $4,00 \mathrm{a}$ & $13,66 \mathrm{a}$ & $0,58 \mathrm{a}$ & $23,53 \mathrm{a}$ & $6,76 \mathrm{~b}$ & $13,34 \mathrm{~b}$ \\
\hline Marca 2 & $3,84 \mathrm{~b}$ & $11,74 \mathrm{~b}$ & $0,56 \mathrm{a}$ & $20,80 \mathrm{~b}$ & $15,99 \mathrm{a}$ & $14,65 \mathrm{a}$ \\
\hline \multicolumn{7}{|l|}{ Caju } \\
\hline Marca 1 & $4,50 \mathrm{a}$ & $11,74 \mathrm{~b}$ & $0,32 \mathrm{~b}$ & 36,70 a & $176,76 \mathrm{a}$ & $13,19 \mathrm{a}$ \\
\hline Marca 2 & $3,77 \mathrm{~b}$ & $12,41 \mathrm{a}$ & $0,60 \mathrm{a}$ & $20,60 \mathrm{~b}$ & $180,34 \mathrm{a}$ & $13,90 \mathrm{a}$ \\
\hline \multicolumn{7}{|l|}{ Cacau } \\
\hline Marca 1 & 3,69 a & $13,09 \mathrm{~b}$ & $0,77 \mathrm{a}$ & $16,98 \mathrm{~b}$ & $1,49 \mathrm{a}$ & $13,17 \mathrm{~b}$ \\
\hline Marca 2 & $3,63 \mathrm{~b}$ & $13,69 \mathrm{a}$ & $0,68 \mathrm{a}$ & 20,16 a & $1,33 \mathrm{a}$ & $14,98 \mathrm{a}$ \\
\hline \multicolumn{7}{|l|}{ Umbú } \\
\hline Marca 1 & $2,64 \mathrm{a}$ & $7,74 \mathrm{~b}$ & $1,36 \mathrm{~b}$ & $5,67 \mathrm{a}$ & $2,13 \mathrm{~b}$ & $8,13 \mathrm{~b}$ \\
\hline Marca 2 & $2,58 \mathrm{~b}$ & $11,07 \mathrm{a}$ & $1,94 \mathrm{a}$ & $5,71 \mathrm{a}$ & $8,42 \mathrm{a}$ & $12,56 \mathrm{a}$ \\
\hline \multicolumn{7}{|l|}{ Graviola } \\
\hline Marca 1 & $3,86 \mathrm{a}$ & $9,66 \mathrm{~b}$ & $0,80 \mathrm{a}$ & $12,09 \mathrm{a}$ & $2,54 \mathrm{~b}$ & $10,88 \mathrm{~b}$ \\
\hline Marca 2 & $3,58 \mathrm{~b}$ & $10,91 \mathrm{a}$ & $0,88 \mathrm{a}$ & $12,36 \mathrm{a}$ & $4,97 \mathrm{a}$ & $12,10 \mathrm{a}$ \\
\hline
\end{tabular}

SST: Sólidos solúveis totais; ATT: Acidez total titulável; ratio: relação SST/ATT; ST: Sólidos totais. Médias seguidas da mesma letra nas colunas não diferem significativamente pelo teste de Tukey ao nível de $5 \%$ de probabilidade.

Em relação à acidez titulável total (ATT) as amostras estão dentro do permitido pelo PIQ, com exceções para as amostras da marca 1 de maracujá com valor de 1,93 e da marca 2 de cacau com valor de 0,68 (Tabela 1). Segundo Dantas et al. (2010) estes baixos valores de ATT podem ser explicados pelo grau de maturação do fruto, uma vez que, à medida que ocorre o amadurecimento, o teor de ácido cítrico diminui. A acidez é um parâmetro importante na apreciação do estado de conservação de um produto alimentício. Geralmente, um processo de decomposição do alimento, seja por hidrólise, oxidação ou fermentação, altera quase sempre a concentração dos íons de hidrogênio, e por consequência a sua acidez (AROUCHA et al., 2010).

Os valores de ATT das polpas de abacaxi e umbu apresentaram valores próximos aos obtidos por Batista et al. (2013) (0,71 g de ácido cítrico/100g) e Machado et al. (2007) (1,47 g de ácido cítrico/100g), respectivamente, entretanto é importante verificar que para o umbu a marca 2 foi estatisticamente superior a marca 1, sendo seu valor superior até mesmo ao observados em outros trabalhos (Tabela 1).

Quanto aos valores de sólidos totais (ST) somente as amostras de caju (marca 1 e 2) e a graviola (marca 2) estão dentro do PIQ estabelecidos pelo MAPA. Este resultado pode 
fortalecer a hipótese de diluição das polpas (acréscimo de água), o que acarretaria uma diminuição na qualidade do produto (GARDELHA et al., 2009). Os valores do umbu e abacaxi (Tabela 1) mostraram-se próximos aos obtidos por Lima et al. (2003) (10,11g/100g) e Gardelha et al.(2009) $(11,72 \mathrm{~g} / 100 \mathrm{~g})$, respectivamente.

O ácido ascórbico também é um indicador de qualidade dos alimentos e pode ser influenciado pelas as condições de cultivo, armazenamento e processamento da matéria prima e produto final (CHITARRA \& CHITARRA, 2005). Dentre as polpas analisadas só existe PIQ para acido ascórbico para a polpa de graviola e caju, sendo que apenas os valores obtidos para a polpa de caju se enquadraram dentro dos parâmetros estabelecidos pela Legislação Brasileira (BRASIL, 2000).

A polpa de abacaxi da marca 1 apresenta valores de vitamina C (ácido ascórbico) próximo aos observados por Dantas et al. (2010) (5,04 mg/100g) o que não se repetiu para a marca 2 (Tabela 2). Os valores de vitamina $\mathrm{C}$ na polpa de umbu mostraram-se diferentes entre as marcas, sendo que a marca 2 apresenta valores aproximadamente quatro vezes maiores que a marca 1 (Tabela 1). Machado et al. (2007) encontraram valores médios em torno de $10,74 \mathrm{mg} / 100 \mathrm{~g}$ resultado este que se aproxima dos observados na marca 2. Já nas amostras de maracujá pode-se observar valores médios de vitamina $C$ de 9,47 e 9,11 mg/100g para as marcas 1 e 2, respectivamente, mostrando-se muito abaixo dos obtido por Batista et al. (2013) e Nascimento et al. (2012) ao observarem 21,78 e 66,72 mg/100g, respectivamente. A não conformidade observada pode estar relacionada às práticas de processamento, exposição à luz, oxigênio e às condições inadequadas de armazenamento, uma vez que o ácido ascórbico é altamente reativo (TEIXEIRA \& MONTEIRO, 2006).

O ratio que é a relação de (SST/ATT) não apresenta parâmetros na legislação brasileira. Dentre as amostras avaliadas a polpa que apresentou maior relação foi a de caju e a de menor foi a de maracujá (Tabela 1). Este resultado ajuda a explicar o porquê das polpas de caju se enquadrarem dentro dos padrões em todos os quesitos e as de maracujá fora destes na maioria das analises. $\mathrm{O}$ ratio verifica o balanço de ácidos e açúcares, deste modo, quando os valores desta relação são altos, significa que o fruto esta em bom grau de maturação, pois esse grau aumenta quando há decréscimo de acidez e alto teor de SST, decorrentes da maturação (CHITARRA \& CHITARRA, 2005).

A partir dos resultados constata-se que apenas a polpa de caju estava de acordo com o regulamento técnico para fixação do padrão de identidade e qualidade. Nascimento et al. (2012) ao avaliarem as polpas de frutas de diferentes marcas (acerola, cajá, cupuaçu, goiaba, e maracujá) comercializadas no município de Boa Vista/RR, verificaram que apenas as polpas de graviola e cupuaçu estavam de acordo com a legislação. Já Silva et al. (2011), ao estudarem polpas de acerola, abacaxi e maracujá comercializadas em Minas Gerais, observaram que a maioria das polpas estudadas são apropriadas para consumo; estes afirmam que o estudo dos parâmetros físico-químicos de polpas de frutas podem servir como um alerta para que se agilize a normatização desses produtos, ao mesmo tempo, em que reflete a real situação desse segmento da Agroindústria, que necessita padronizar, além do produto, o processo tecnológico para obtenção de uma polpa com qualidade, a fim de possibilitar a conquista de novos mercados. Além disso, as autoridades fiscalizadoras devem tomar providências mais intensivas a fim de corrigir as irregularidades encontradas, devido aos aspectos legais, de direitos do consumidor e de saúde pública (LIMA et al., 2015).

Além disso, foi observado que vários parâmetros analisados apresentaram valores bem abaixo do estabelecido. Resultado semelhando foi obtido por Batista et al. (2013) ao estudarem as polpas produzidas no Alto Vale do Jequitinhonha.

\section{CONCLUSÕES}

Constata-se que houve grande divergência entre as marcas de polpas de frutas analisadas, podendo assim afirmar que de forma geral a marca 2 apresentou maior qualidade com relação a marca 1. Entretanto para as duas marcas avaliadas o único sabor que atendeu a todos os parâmetros físicoquímicos padronizados pela instrução normativa foi a polpa de fruta sabor caju, o que compromete a qualidade prejudicando o consumidor.

\section{REFERÊNCIAS BIBLIOGRÁFICAS}

AROUCHA, E. M. M.; GOIS, V. A.; LEITE, R. H. L.; SANTOS, M. C. A. SOUZA, M. S. Acidez em frutas e hortaliças. Revista Verde de Agroecologia e Desenvolvimento Sustentável, Mossoró, v. 5, n. 2, p. 0104, 2010.

ARRUDA, M. G. P.; MATOS, V. C.; CASIMIRO, A. R. S.; TELLES, F. J. S. Incidência de fungos em polpas de cajá produzidas no município de Fortaleza: Uma análise comparativa entre os métodos convencional e simplate. Higiene Alimentar, São Paulo, v.20, n.141, p.94-97, 2006.

Association of Official Analytical Chemists. Official methods of analysis of AOAC international, 16.ed. Gaitherburg: Patricia Cunniff, 1997. v.2, 1141p.

BATISTA, G. A.; OLIVEIRA, B. D.; OLIVEIRA, M. A.; GUEDES, T. J.; SILVA, D. F.; PINTO, N. A. V. D. Parâmetros de qualidade de polpas de frutas congeladas: uma abordagem para produção do agronegócio familiar no Alto Vale do Jequitinhonha. Tecnologia \& Ciência Agropecuária, João Pessoa, v.7, n.4, p.49-54, 2013.

BENASSI, M. T.; ANTUNES, A. J. A. Comparison of metaphosphoric and oxalic acids as extractant solutions for the determination of vitamin $\mathrm{C}$ in selected vegetables. Arquivos de Biologia e Tecnologia, Curitiba, v.31, n.4, p.507-513, 1998.

BRASIL. Agência Nacional de Vigilância Sanitária. Resolução RDC no 12, de 02/01/2001. Regulamento Técnico sobre padrões microbiológicos para alimentos. Diário Oficial da República Federativa do Brasil, Brasília, DF, 2001.

BRASIL. Ministério da Agricultura e do Abastecimento. Instrução Normativa $N^{\circ} 1$, de 7 de janeiro de 2000. 
Regulamento técnico geral para fixação dos padrões de identidade e qualidade para polpa de frutas. Diário Oficial da União, № 6, Brasília, 10 de janeiro de 2000.

CALDAS, Z. T. C.; ARAÚJO, F. M. M. C.; MACHADO, A. V.; ALMEIDA, K. L. A. Investigação de qualidade das polpas de frutas congeladas comercializadas nos estados da Paraíba e Rio grande do norte. Revista Verde de Agroecologia e Desenvolvimento Sustentável, Mossoró, v. 5 , n. 4 , p. $156-163,2010$.

CHITARRA, M. I. F.; CHITARRA, A. B. Pós-colheita de frutas e hortaliças. 2 ed. Editora UFLA. Lavras. 2002. $783 p$.

DANTAS, R. L.; ROCHA, A. P. T.; ARAUJO, A. S.; RODRIGUES, M. S. A.; MARANHAO, K. L. Perfil da qualidade de polpas de fruta comercializadas na cidade de Campina Grande/PB. Revista Verde de Agroecologia e Desenvolvimento Sustentável, v.5, n.5, p.61-66, 2010.

GADELHA, A. J. F., ROCHA, C. O., VIEIRA, F. F.; RIBEIRO, G. N. Avaliação de parâmetros de qualidade físico-químicos de polpas congeladas de abacaxi, acerola, cajá e caju. Revista Caatinga, Mossoró, v. 22, n.1, p.115$118,2009$.

IAL, Instituto Adolfo Lutz. Métodos físico-químicos para análise de alimentos. São Paulo: Instituto Adolfo Lutz, 2008. $1020 \mathrm{p}$.

LIMA, T. L. S.; CAVALCANTE, C. L.; SOUSA, D. G.; SILVA, P. H. A.; SOBRINHO, L. G. A. Avaliação da composição físico-química de polpas de frutas comercializadas em cinco cidades do Alto Sertão paraibano. Revista Verde, v. 10, n.2, p.49 - 55, 2015.

LIMA, I. J. E.; QUEIROZ, A. J. M.; FIGUEIRÊDO, R. M. F. Propriedades termofísicas da polpa de umbu. Revista Brasileira de Produtos Agroindustriais, Campina Grande, Especial, n.1, p.31-42, 2003.

MACHADO, S. S.; TAVARES, J. T. Q.; CARDOSO, R. L.; MACHADO, C. S.; SOUZA, K. E. P. Caracterização de polpas de frutas tropicais congeladas comercializadas no Recôncavo Baiano. Revista Ciência Agronômica, Fortaleza, v.38, n.2, p.158-163, 2007.

MACHADO, A.V. Estudo da secagem do pedúnculo do caju em sistemas convencional e solar: modelagem e simulação do processo. Natal 2009. p.126, Tese Doutorado em Engenharia Química, Universidade Federal do Rio Grande do Norte.

MATSUURA, F. C. A. U., ROLIM, R. B. Avaliação da adição de suco de acerola em suco de abacaxi visando à produção de um "blend" com alto teor de vitamina C. Revista Brasileira de Fruticultura, Jaboticabal, v.24, n.1, p.138-141, 2002.

MORAIS, F.A.; ARAÚJO, F. M. M. C.; MACHADO, A. V. Influência da atmosfera modificada sob a vida útil pós- colheita do mamão 'formosa'. Revista Verde de Agroecologia e Desenvolvimento Sustentável, Mossoró, v.5, n.4, p.01-09, 2010.

NASCIMENTO, C. R.; NEVES, L. C.; GRÍGIO, M. L.; CAMPOS, A. J.; CHAGAS, E. A.; SOUZA, A. A. Avaliação da qualidade de polpas de frutos industrializadas e comercializadas no município de Boa Vista - RR. Revista Agroambiente, Boa Vista, v. 6, n. 3, p. 263-267, 2012.

PINHEIRO, A. M.; FERNANDES, A. G.; FAI, A. E. C.; PRADO, G. M.; SOUSA, P. H. M.; MAIA, G. A. Avaliação química, físico-química e microbiológica de sucos de frutas integrais: Abacaxi, caju e maracujá. Ciências e Tecnologia de Alimentos, Campinas, v. 26, n.1, p.98-103, 2006.

SANTOS, F. A.; SALLES, J. R. J.; CHAGAS FILHO, E.; RABELO, R. N. Análise qualitativa das polpas congeladas de frutas produzidas pela SUFRUTS, MA. Revista Higiene Alimentar, São Paulo, v.18, n.119, p.1422, 2004.

SILVA M. S. S; FIGUEIRÊDO R. M. F.; QUEIROZ A. J. M.; SANTIAGO V. M. S. Avaliação físico-química e sensorial de doces cremosos produzidos com soro de leite de cabra, leite de vaca e polpa de umbu. Revista Brasileira de Produtos Agroindustriais, Campina Grande, v.13, n.Especial, p.397-410, 2011.

SILVA, J. W. P.; SILVA, N. A.; BORGES, D. O.; SANTOS, C. G. P.; RODRIGUES, L. M. Estudo de parâmetros físico-químicos de qualidade para polpas de acerola, abacaxi e maracujá. FAZU em Revista, Uberaba, n. 8, p. 89-94, 2011.

SILVA, F. A. S. E.; AZEVEDO, C. A. V. de. Versão do programa computacional Assistat para o sistema operacional Windows. Revista Brasileira de Produtos Agroindustriais, Campina Grande, v.4, n.1, p71-78,2002.

TEIXEIRA, M.; MONTEIRO, M. Degradação da vitamina C em suco de frutas. Alimentos e Nutrição, Araraquara, v.17, n.2, p.219-227, 2006. 